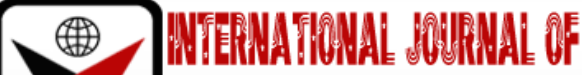 \\ בmRक
}

ISSN 2278-0211 (Online)

\section{Efficiency of Implementation of Modern CNC Equipment for Production of Heat Reducer Shafts}

Ezekiel Oluwadamilare Akintona
Assistant Lecture, Department of Industrial and Production Engineering,
Nnamdi Azikiwe University Awka, Anambra State, Nigeria
Azeez Oladipupo Bakare
Department of Mechanical Engineering,
East Ukrainian National University, Lugansk Ukraine, Nigeria
Ezeanyim Okechukwu Chiedu
Lecturer, Department of Industrial and Production Engineering,
Nnamdi Azikiwe University Awka, Anambra State, Nigeria

\begin{abstract}
:
The article analyses the capabilities of modern metal-working equipment with numerical program control (CNC) and the efficiency of its use in the processing of gear shafts of diesel locomotives. Figure. 3 the strategy of accelerating the socio-economic development of the country provides for the comprehensive intensification of production on the basis of scientific and technological progress. One of the effective ways to solve the problem of intensification of production, increase productivity is the introduction of modern CNC metalworking equipment and modern cutting tools. The industry has accumulated extensive experience in the use of CNC machines, which in comparison with conventional equipment create a number of technical and economic advantages. The productivity of these machines is three times higher than in machines of the same type without software control, and the need for production space is three times less. The greatest effect is given by CNC machines at processing of surfaces of difficult form and big accuracy therefore their use allows to reduce highly skilled workers.
\end{abstract}

Keywords: Computer Numerical Control (CNC), gear shaft of diesel locomotives

\section{Introduction}

Technological preparation of production, for tool sharpening, maintenance of VTK controllers. [1].The main effect of $\mathrm{CNC}$ equipment is to increase up to $80-90 \%$ of the operating time of the equipment $(15-20 \%$ for conventional machines). This is due to the fact that the auxiliary time for tool replacement and hardware readjustment is sharply reduced, which in this case is to replace the program recorded on magnetic tape or other electronic media, and in some cases to replace tools. The wide range of work performed by CNC machines is high accuracy and quality of the processed surfaces, does them especially valuable in unit and small-scale production, and also at the enterprises letting out difficult production. There is experience of inclusion of CNC machines in production lines at the enterprises of serial and mass productions. Under modern conditions, such type of programmable equipment as machining centers, which are multioperational CNC machines and automatic tool change, is widely used. According to experts, machining centers are equivalent in their productivity to 3-4 CNC machines, or 8-12 conventional machines [2][3]. With the right choice and rational operation, the cost of purchasing machining centers pays off in 3-4 years. For effective use of CNC machines it is necessary to create a system of organizational support. It should be a set of interacting measures, subject to the main task the manufacture of high quality parts in a timely manner with minimal labor costs and cost. The system of work organization should include a feasibility study for the use of CNC machines, the range of parts for machining, proper maintenance of machines, automated development of control programs. An important task is to choose the type of machine and processing technology. In this case, determine the cost-effectiveness of the selected option and the main processing time of the parts depending on the method of processing.

\section{Methodology}

2.1. The Effectiveness of the Selected Option Is Evaluated by the Proportion of the Main Processing

Time: $\mathrm{KP}=\mathrm{T} / \mathrm{TP}$

Where: $\mathrm{T}$ - the main processing time, min;

TP - production time, i.e., the total manufacturing time of the part on the CNC machine, min. 
CNC turning and milling machining centers are now indispensable equipment in almost any production, which is used for processing various parts and industrial products. Ease of use, speed and technical performance of turning and milling machining centers make them popular and in demand in the market of metal-working equipment. Thanks to electronic technologies turning and milling CNC machining center can significantly reduce machining time, which allow increasing production. In addition to the speed of processing, an important indicator is the accuracy of its execution. Cutting tools for OC machines must have certain dimensions. This is due to the type of tool shop used and the work of the operator. The CNC device allows to process details with high accuracy (IT5...IT6) that allows letting out qualitative production with the minimum expenses of time. Speed and interchangeability of the tool provide reduction of downtime of the equipment at tool replacement and readjustment of the machine. This is provided by a special auxiliary tool with precision surfaces. To ensure speed, the tools are pre-adjusted to the size outside the machine. For processing of flat surfaces it is recommended to apply face end mills with insert knives from high-speed steel, a hard alloy. This design eliminates soldering and sharpening of hard alloy plates, thereby providing increased stability of the cutting edges. Holes can be obtained by drilling, boring, countersinking, milling. Cast holes are first drilled to reduce the diversion of the hole axis. When counter-sinking, use a tool with a main angle in the plan equal to or close to 90 degrees. The axial forces less deform the tool rod. Boring tool: usually consists of a mandrel and cutting elements in the form of a cutter or chisel insert. It must have a small, permissible hole size, diameter, and the smallest length. Increasing the length reduces the stiffness and reduces the processing performance and quality of the treated surface. The cutting tool is applied standard and special to which the increased requirements on accuracy, rigidity, speed of change and adjustment on the size, stability, stable chip removal, reliability are shown. Auxiliary tools are mainly used assembly, which, although it has a slightly lower stiffness compared to the solid, but well dampens the vibrations arising during processing. Blade cutting tool made of synthetic super hard materials (VTM) - cubic boron nitride and polycrystalline diamonds, allows processing with cutting speeds an order of magnitude higher than hard alloys. It is applied at turning, milling, drilling, development, arrangement, cutting of details from pig-iron and hardened steels, non-ferrous alloys, the newest difficult-to-process composite materials and alloys not only in mass and large-scale, but mainly in serial and small-scale production, and even individual. Approximately $75 \%$ of all machine-building products. The main prerequisite for the effective use of VTM tools in automated processes on CNC machines, machining centers, special machines, and automatic lines is the ability to implement optimal for VTM high cutting speeds. A sharp increase in speed, other things being equal, provides a corresponding increase in the minute feed of the tool, i.e., process productivity, as well as reducing the cutting force, hardening and roughness of the treated surface, i.e., the accuracy and quality of processing.

\subsection{The Economic Effect of the Introduction of Turning and Boring Cutters}

Cutters and other blade tools based on cutting elements with VTM for high-speed cutting of difficult-to-machine materials with speeds of $500 \ldots 3000 \mathrm{~m} / \mathrm{min}$ is provided by increasing the cutting speed by 5 ... 10 times processing productivity of $1.5 \ldots 10$ times, the stability of the tool at least an order of magnitude, accuracy and quality of surface treatment compared to carbide tools. In addition, high speed allows in many cases to carry out processing without coolant, i.e., the so-called 'dry' cutting, which reduces costs and improves the environmental situation in the workplace, as well as reduces harmful emissions into the environment. This article presents the results of the calculation of economic benefits in production due to the improvement of the basic technological process, namely the replacement of basic equipment used for machining a group of parts such as 'shaft' with the latest equipment. The HURCO TMM 10 turning and milling center is used as the newest equipment (Figure. 1).

\section{Technical Characteristics of the HURCO TMM 10}

Turning and milling center working area:

Maximum diameter of processing: $295 \mathrm{~mm}$

Maximum length of processing: $700 \mathrm{~mm}$

Diameter of the cartridge: $250 \mathrm{~mm}$

Maximum diameter of a bar: $76 \mathrm{~mm}$

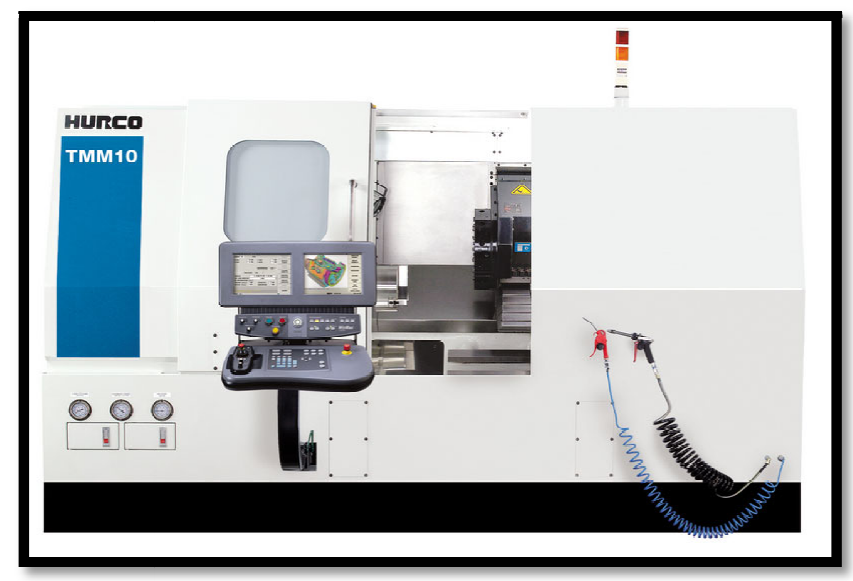

Figure 1: Turning and Milling Center HURCOTMM 10 
Displacement:

$\mathrm{X}$-axis, $250 \mathrm{~mm}$

Z-axis, $750 \mathrm{~mm}$

Feed, X / Z, 19 m / 24 min

Spindle motor:

Power, $18 \mathrm{KW}$

Spindle:

Rotation speed, 3000rpm

Torque, $474 \mathrm{Nm}$

Turret:

Type according to DIN 5480 VDI 40

Number of stations 12

Tool change time, $\mathrm{p}, 0.31$

The basic technological process uses a large amount of equipment to perform various operations, but the load of many machines is small. In this regard, the equipment used is idle and has no opportunities to pay off and even more so to make a profit. In addition, it is quite irrational to use the working time of workers, for example, the artificial time for radial drilling is only 1.5 minutes, while the timing of the shafts is 5.06 minutes. Thus, the load factor of this machine Kzv = 0.296, which is too small (Figure.2). In the proposed process, the combination of this operation and turning with CNC in the turning and milling allowed to achieve $\mathrm{Kzv}=0.79$, which is fully consistent with this type of production.

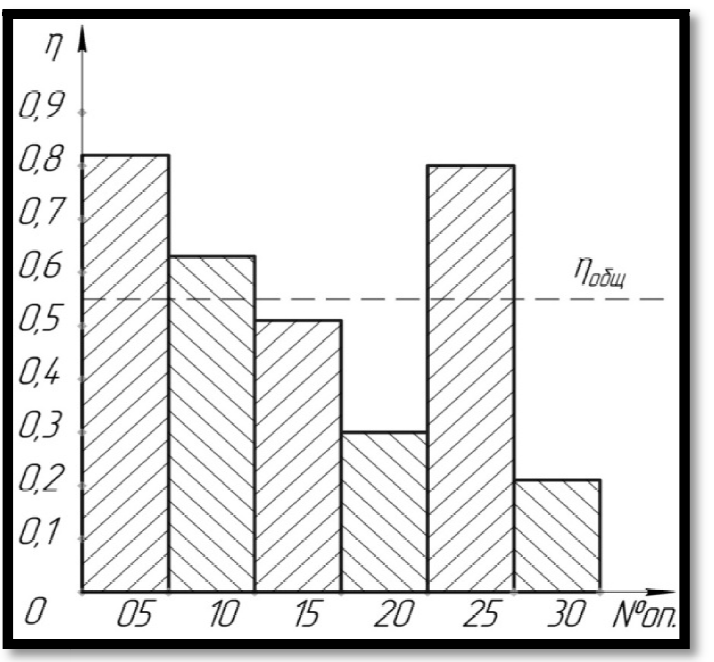

Figure 2: Loading of Machines on the Basic Technological

Process:

05 - Milling and centering;

10- Lathe with CNC;

15- Key-milling;

20- Radial drilling;

25-30 - Circular grinding

The use of turning and milling centers allows not only to combine operations and increase the load factor of the equipment to the most rational values, but also to reduce the amount of auxiliary time for installation and removal of parts, and thus reduce the overall processing time. In addition, the introduction of production the process of the latest CNC technologies allows the use of less skilled workers, which brings considerable economic benefits to production. During the modernization of the basic technical process, the number of machine operators was reduced by $50 \%$, which primarily affected highly qualified workers. It should also be noted that due to the replacement of machines of rigid specialization with turning and milling centers, it is possible to reduce the area occupied by the production site, which entails a reduction in the cost of maintaining the premises, its lighting and more.In a more detailed consideration of the capabilities of modern turning and milling equipment, attention was paid to its high accuracy of processing, which allows achieving the required surface parameters without resorting to energy-intensive grinding operations. In the basic technological process there was a circular grinding operation 30 with a low load factor of equipment (Kzv = 0.21). Using the capabilities of the HURCO TMM 10 center. We replace it with an additional transition in the turning and milling operation - fine turning. As a result, the loading of the equipment of the proposed process takes the optimal form (Figure.3). 


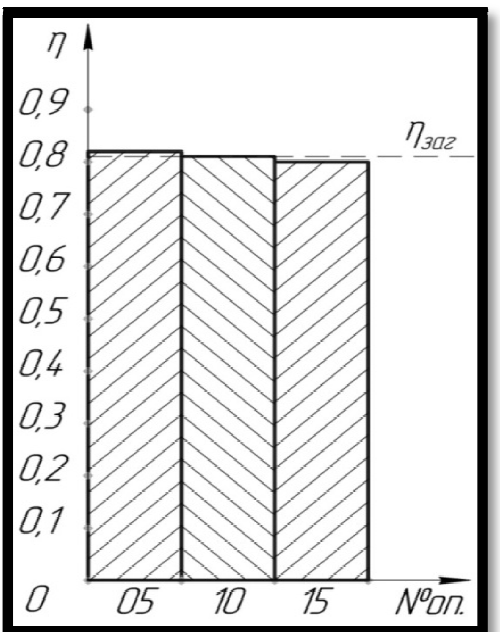

Figure 3: Loading Of Machines on the offered Technological

\section{Process}

05 - Milling and centering;

10 - Turning and milling;

15 - Circular grinding.

Since most of the time of the circular grinding operation took time for the institutions and the removal of parts, the decision to get rid of this operation does not significantly increase the time of turning and milling, which gives quite significant savings. The average load factor of the machines is Kzv $=0.81$, which fully corresponds to the serial type of production.

\section{Conclusion}

- In the course of the research the efficiency of introduction of the turning and milling center which provides performance of various operations on processing of surfaces of a shaft at a minimum of auxiliary actions connected with installation, fastening, removal of the processed detail, and change of the cutting tool etc. was analyzed.

- Replacement of equipment with the latest high-tech allows reducing the complexity of manufacturing shafts by $23 \%$, reducing the number of units of equipment and workers twice, reduce the area, improve working conditions, which contributes to the effective implementation of turning and milling centers in production.

\section{Conflict of Interest}

On behalf of all authors, the Corresponding author states that there is no conflict of interest.

\section{References}

i. Chesnokov OV Technological processes for CNC equipment: a textbook / OV Garlic. - Luhansk: published by SNU. V. Dalya, 2012. - 136p.

ii. Serebrenitsky PP Programming of automated equipment: a textbook for universities: in 2 hours, Part 1. / PP Serebrenitsky, AG Shirtladze. - М .: Дрофа, 2008. - 576 c.

iii. Cutting modes for lathes and drilling-milling-boring machines with numerical program control: reference book / Ed. YOU. Гузеева. М .: Mashinostroenie, 2005. 368 s. 